Association for Information Systems AIS Electronic Library (AISeL)

ICIS 1980 Proceedings

International Conference on Information Systems

1980

\title{
CONTRIBUTIONS OF THE MANAGEMENT SCIENCES TO THE EVOLUTION OF MANAGEMENT INFORMATION SYSTEMS
}

Kenneth E. Kendall

University of Nebraska-Lincoln

Charles H. Kriebel

Carnegie-Mellon University

Follow this and additional works at: http://aisel.aisnet.org/icis 1980

\section{Recommended Citation}

Kendall, Kenneth E. and Kriebel, Charles H., "CONTRIBUTIONS OF THE MANAGEMENT SCIENCES TO THE EVOLUTION OF MANAGEMENT INFORMATION SYSTEMS" (1980). ICIS 1980 Proceedings. 20.

http://aisel.aisnet.org/icis1980/20 


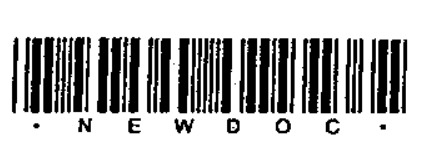


CONTRIBUTIONS OF THE MANAGEMENT SCIENCES TO THE EVOLUTION OF MANAGEMENT INFORMATION SYSTEMS

KENNETH E. KENDALL

College of Business Administration University of Nebraska-Lincoln

CHARLES H. KRIEBEL

Graduate School of Industrial Administration

Carnegie-Mellon University

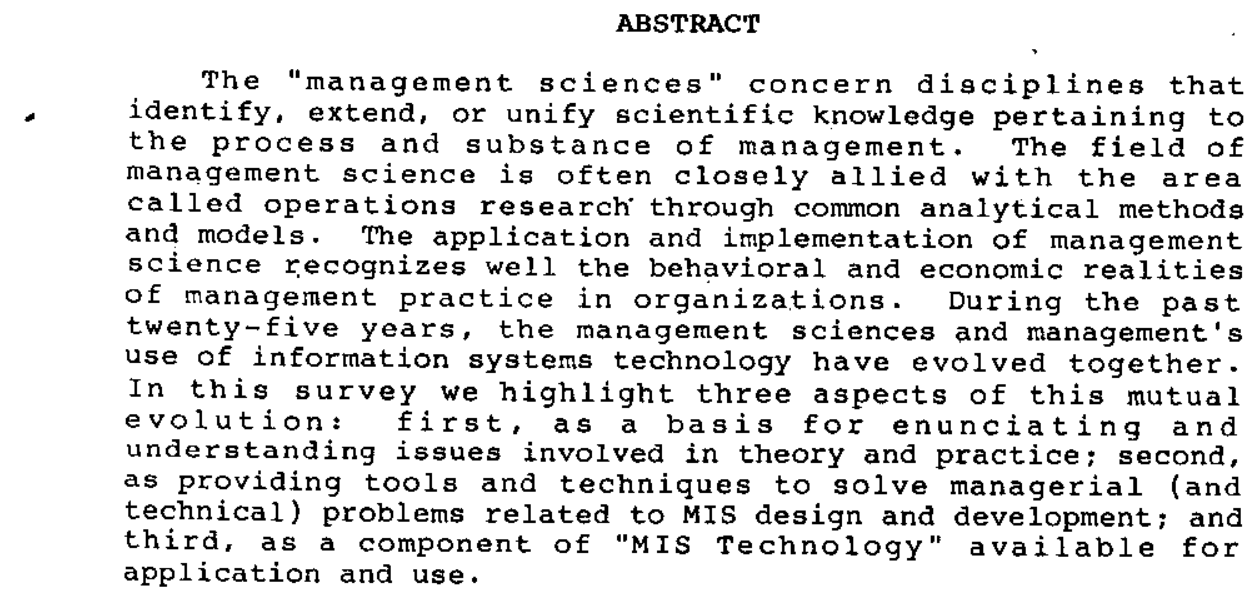

\section{INTRODUCTION}

Processing information is a fundamental activity of management. It plays a central role in all aspects of managerial behavior, in communication, in problem solving, and in decision making. The phrase "management information system(s)" and its acronym MIS have entered our vocabulary as the designate for the formal configuration of human and capital resources that an organization employs to process data in support of the information requirements of its management. During the past twenty-five years, advances in computer and communications technology have enhanced by more that six orders-of-magnitude our capability to process data and supply information. But over this same time frame managements ' demand for better information has expanded at an even greater pace. The result has been ever increasing pressure on those professionals identified with the area of MIS to improve performance. In pursuit of progress the MIS professional has looked for answers beyond his own experience base from other fields and disciplines.
The "management sciences" concern disciplines that identify, extend, or unify scientific knowledge pertaining to the process and substance of management. The application and implementation of management science recognizes well the behavioral and economic realities management practice in organizations. As a core of disciplines, the management sciences, to a great degree, have evolved in parallel with managements' use of modern information systems technology. Obviously, this has not been serendipity; the management sciences have contributed significantly to progress in MrS. In this survey we highlight three aspects of this mutual evolution and the contributions of management science: first, as a basis for enunciating and understanding issues involved in theory and practice; second. as providing tools and techniques to solve managerial (and technical) problems related to MIS design and development; and third, as a component of the "technology" of MIS for application and use.

\section{TOWARDS UNDERSTANDING ISSUES}

In their seminal article Leavitt and 
Whisler (32) were among the first to speculate on how management science and information technology would impact the firm twenty-five years hence. One of their controversial prophecies was the diminishing role of middle management (as known in the late $1950^{\prime} \mathrm{s}$ ), due to an increased automation of middle management functions through the implementation of analytical models on computer systems. In 1960 Simon (56), laid the groundwork for the (now more conventional) view of the organizational entity as an information processing system. That is, in contrast to the traditional economics focus on capital and labor inputs, Simon's paradigm concentrated on information processing activities per se: problem solving, decision processes, memory and their structure. He also sharpened the concepts of "programmable and non-programmable" decision processes for the existing and potential roles of management science in (computer-based) information systems. In sum: he introduced new ideas for thinking about traditional issues in a changing environment.

An early conference on management in the future is reportd in Anshen and Bach (5B). At that symposium simon elaborated on the organizational paradigm in his thought-provoking essay: "The Corporation: Will it be managed by machines?" The theme of the symposium stressed the necessity of corporations and managers to effectively adapt to major changes in their internal and external. environments during the next twenty-five years. Some of the difficulties in making this adaptation became manifest in the presentations and discussions by participants at one of the first research conferences devoted specifically to the MIS area ( 31 ). Perhaps due to latent adolescence, the circumstances did not appear significantly improved from the discussions at a follow-on conference on MIs research held five years later (44). some of these difficulties stem from a lack of universal understanding of the complexities inherent in establishing system structure, i.e., the design environment for MIS. Others relate directly to the more general question of implementation and the role of agents for organizational change.

For example, in Simon (56) the now classic taxonomy of the decision process was developed, consisting of three stages of activity: "intelligence, design and choice." Some reasoned that the "choice stage" was the primary payoff area for MS/OR model applications and that "choice decision models" could be "programmed" independent of considerations for information structure. Pounds (48) provided an interesting paradigr for gaining insights into the earlier stages of decision processes. Kriebel (30) investigated the design implications of interdependence between decision and information structures for the well known quadratic production smoothing problem. Ackoff's seminal article (1) challenged what he perceived to be commonplace assumptions in MIS design and proposed an alternative approach to the process. In a similar but more philosophical vein, simon (55) develops the tenets of a theory for a "science of design" in general.

Awareness of the multi-dimensionality of MIS design and evaluation was provided in the early Mckinsey \& Company surveys reported by Garrity (18). Here too, the early and perceptive article by Daniel (14) has more recently been refined into an operational framework for isolating "critical" MIS requirements, Rockart (51). The relationship between performance and MIS use has also been the subject of modeling efforts, e.g., Lucas (37). Notable in the early work on understanding the issue of implementation, is Churchman and schainblatt $(10)$ and the research of Radnor (49). An excellent synthesis of this research is available in $\mathrm{zand}$ and Sorensen (62).

The management sciences and the area of MIS, as such, are roughly twenty-five years young. While progress has materialized in both areas and there have been reciprocal contributions towards mutual development, our understanding of numerous issues remains elusive. The conference proceedings, (31) and (44) cited above, provide examples of some of the directions management science has pursued in MIS research historically. Van Horn (60) reviews representative empirical work. Ives, Hamilton and Davis (26) survey more recent doctoral dissertations on MIS and propose a framework as a guide for future research efforts.

\section{MIS PROBLEM SOLVING}

In addition to applications in computer science, MIS design and operation have benefited considerably from the use of MS/OR tools. Coding,. storing, retrieving data, and the scheduling of computer usage have been major areas addressed with these techniques. Techniques employed include mathematical programming, queuing, and simulation. These are surveyed below.

\subsection{STORING, RETRIEVING AND MANIPULATING} DATA

Chandra et al. (9) investigates the lower bound characteristic of a mathematical programming algorithm which 
minimized the number of storage cells required for a computer data bank. De, et al. (15) utilize a zero-one matnematical program to minimize the total of storage and access costs of databases. A network structure is developed to describe the system modeled. A dynamic programing formulation for locating files in distributed computer networks is developed by Levin and Morgan (33). Problems addressed arose from the use of common carriers to communicate between decentralized terminals.

A queuing system model is simulated by Nance and Bhat (47) to analyze job flow in a multiprocessor computer system. They employ an embedded Markov chain to model system utilization, and use it to simulate systems with two or more interconnected processing units. Sockut (57) investigates a two priority queuing model to analyze the reorganization of a data base during usage. A network of queuing systems is developed by siegel and Torelli (54) to evaluate information processing nets. Centralized processing networks were found to have less delay than distributed processing networks, because of relative data flow volumes.

Coffman and hofri (11) model secondary memory devices as single-server queuing systems. Their study deals with congestion points occuring at interactions between secondary storage units, where service time is a function of the prior location of the data requested. Simulation of job response time is applied to networks of queues by Iglehart and shedler (25). They use a Markov renewal process to generate arrivals to the networks. The model represents the workload to a computer system.

\subsection{MIS DESIGN}

Lucas (36) reviewed research in the design of management information systems and found that "heuristic decision makers" would use models for decision support more than "analytic decision makers." contradicting prior anticipations. More user control in the MIS design process was recommended to foster management acceptance. Raiborn and Harris (50) discuss the use of a "systems approach" to model design. Their article analyzed the use of linear programing and EOQ models in inventory management information systems. The authors propose beginning with simple analytic components for the system and enriching them subsequently, as evidence of benefits is obtained. The significant work by the group at the University of Minnesota investigated various MIS design characteristics and their impact on decision performance, see Dickson, et al. (16).
Recently, Meyer (42) stressed the common goals and complementary functions of management science and $M I S$ in the context of "office automation" and identified the areas of support management science can provide. He considered MS/OR tools useful in office automation design through the analysis of information flows, the establishment of measures of effectiveness, and the development of analytical models. An earlier symposium on the application of MS/OR tools for the solution of EDP problems is available in Hanssmann (21). An excellent collection of readings on more general tehniques for systems analysis and design and their chronological development is provided by Couger and Knapp (12).

\section{COMPONENTS OF MIS TECHNOLOGY}

The articles surveyed in this section discuss design, development and implementation of information systems in which one or more traditional MS/OR techniques are integral components of the systems as it is implemented to support decision processes in an organization $(3,4)$. All of this literature share two common characteristics:

First, the major contribution is service provided by the MIS/DSS rather than the specific solution obtained by the MS/OR tool(s) employed; and

Second, the system described is not only used for planning and decision making, but for management control as well.

The discussion is organized according to the level of the organization most directly affected by the information system.

\subsection{OPERATIONS MANAGEMENT}

One of the early applications of an interactive DSS in the marketing area was the work by Little and his colleagues at MIT (35). Another early application was Garrity's portfolio management system (19). Repetitive, but semi-structured decisions on portfolio selection were aided by manipulation and analysis of statistical data. Ahlers (2) later used a combination of linear programming, economic forecasting and statistical analysis for investment decision making. Both of these financial models placed a high priority on tailoring the DSs towards the style of the decision maker.

Industrial applications have naturally received considerble attention. For example, Beatson (6) describes an embedded optimization algorithm in a foundry. The 
system, which improved the efficiency of controlling die stocks, is of interest because it allowed a review of previous decisions. An integrated DSS at an aluminum smelter was presented by Blake (7). Three MS/OR models are described: a forecasting model to predict future work requirements, a simulation model for scheduling, and a model that manipulated payroll data to generate information useful in labor relations. An excellent DSS incorporating a variety of sophisticated MS/OR techniques was reported by King and Love (29). This article describes the use of inventory models, forecasting packages, linear and dynamic programming decomposition techniques, and heuristic models for sales forecasting, production planning, and distribution at an operating division of Kelly-Springfield.

Information systems for tracking and managing the distribution of human blood for a regional medical center were made possible through the application of MS/OR models. Frankfurter et al. (17) developed and implemented a short-term forecasting system based on exponential smoothing. Completed with committee forecasts, it operated as a DSS for calling in blood donors. Brodheim and prastacos (8) described a system using machine-readable bar codes to collect information, and a dynamic programming model for allocating units of blood to hospitals to minimize outdating and blood shortages. Independent of this effort, Kendall and Lee (28) developed a DSS which handled multiple objectives for a regional center and used a goal programming model to add some structure to the blood distribution problem.

Other articles exemplifying the use of MS/OR models in information systems include Tobin's (59) comprehensive discussion of their use in the airline industry. Here an interactive, timesharing system is discussed, focusing on five MS/OR models used to schedule aircraft, monitor operational plans, simulate schedules, assign air crews, and analyze route profit. The application of information systems to human resource management using (and proposing) various MS techniques is discussed by Hude and Shafritz (24).

\subsection{MANAGEMENT PLANNING AND CONTROL.}

In 1970, Montgomery and Urban (43) proposed a decision-information system in a classic article on marketing information systems. They depicted the need for numerous MS/OR techniques to be included in the MIS. In the same year Stephenson (58) described such a system for division planning. Hill-climbing optimization, mathematical programming, and stimulation were used in this DSS.

Scott Morton's (45) description of the DSs of an appliance firm is a pioneering effort in aiding the decision maker with semi-structured problems. This was followed by numerous articles describing DSS for middle management, e.g.. Alter (3). Mclean and Riesing (40) introduced a DSS development to support costing, p 1 anning, and budgeting. Their interactive system and its statistical analysis component provided a new concept for use in budgetary control. The advantage of combining user judgment and MS/OR tools was recognized by Lewy (34) who described a computer simulation of coal mining operations for a medium-range planning horizon.

The semi-structured nature of decision making in blood banking is due in part to the short life of human blood. Two very different approaches toward decision support took advantage of MS/OR models to simplify some, but not all, of the blood administrator's problems. Cuming et al. (13) described a tabular and graphical DSS based on a Markovian population model. This system is used to schedule bloodmobiles for six to twelve months into the future. Kendall (27) discussed how a decentralized DSS is useful for improving attainment of professional objectives (e.g., blood quality) but less effective in improving administrative (e.g., inventory control) objectives.

An article relevant to problem identification for management planning reviews is (5). Anderson and Janson discussed three methods of cause and effect analysis in identifying problems. This effort attempts to use MS/OR techniques in this often-neglected function of an information system.

\subsection{STRATEGIC PLANNING}

The use of MS/OR techniques as a part of an MIS/DSS for strategic planning developed later than the previous two areas. One of the early conferences in this area is reported in Schrieber (53) and contrasts somewhat with more recent experience a decade later (52). In 1974, Meader and Ness (41) and Hamilton and Moses (20) reported on systems for corporate planning.

Meader and Ness investigated the reportedly low use of interactive information systems, and designed a planning support system that relied on a goal programming model, exponential smoothing, and statistical analysis. Emphasis was once again placed on decision making style. Hamilton and Moses's system 
included optimization, simulation, econometric forecasting, and risk analysis subsystems. Moses (46) described another implementation of a strategic planning system, this one in a large. multi-subsidiary firm.

Socio-Political decision problems are discussed by Higgins and Romano (22). MS/OR techniques included in the MIS were simulation, statistical decision theory and regression. Wyman (61) described a simulation used to justify and design a tar sands mining project. Originally used in long-range planning, the model was continued in use as a tool for operations refinement.

\section{SUMMARY}

This survey has attempted to highlight some of the contributions the management sciences have made to the area of management information systems. In approaching that task we organized the discussion around three dimensions of impact: towards an understanding of fundamental issues in theory and practice; in providing tools and techniques for solving operational problems in MIS; and in becoming integral components of actual MIs technology. Obviously, in the space available it was impossible to do justice to the vast literature that has become available in this context during the past twenty-five years. Consequently, the sixty odd references cited should be taken as indicative of the work done, but a very small sample of it. For contrast, the recent OR/MS index for the cumulative years 1952-1976 contains nearly 5000 articles in a wide variety of fields, (38); and this index only covers three current journals. We believe the evidence of a productive co-evolution of the management sciences and the area of MIS is good, and perhaps strong. This progress notwithstanding, the caveats raised by Mason (39), remain good advice in the pursuit of future progress.

\section{REFERENCES}

1. Ackoff, R.L. Management misinformation systems. Management Science, 144,4 , (December $19 \overline{6} \overline{7}$ ), B14 $\overline{7}-\mathrm{B} 15 \overline{6}$.

2. Ahlers, D.M. An investment decision making system. Interfaces, $5,2-2$, (February 1975), 72-90.

3. Alter, s. How effective managers use information systems. Harvard Business Review, (Nov.-Dec. 1976), 54, 6, $97-104$.
4. Alter, S. A taxonomy of decision support systems. Sloan Management Review, 19, 1, (Fa11 1977), 39-56.

5. Anderson, J.C. and Janson, M.A. Methods for managerial problem cause analysis. Interfaces, 9,5 , (November 1979). $121-128$.

5B. Anshen, M. and Bach, G.L. (ed.).

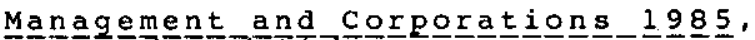
McGraw-Hìi, (1960).

6. Beatson, R. Optimal die stock control at Firth Vickers foundry. Journal of the Operational Research Society, 30, (1979), 1077-1084.

7. Blake, S. Aids to decision making at an aluminum smelter. Journal of the Operational Research Society, $30,(1979)$, $1063-1067$

8. Brodheim, E. and Prastacos, G. The Long Island blood distribution system as a prototype for regional blood management. Interfaces, 9, 5, (November 1979), 3-20.

9. Chandra, A.K., Hirschberg, D.S. and Wong, C.K. Bin packing with geometric constraints in computer network design.

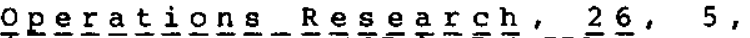
Tseptember-0ctober $1 \overline{9} 78$ ), $76 \overline{0}-772$.

10. Churchman, C.W. and Schainblatt, A.H. The researcher and the manager: A dialectic of implementation. Management Science, 11, (February 1965), B69-B78.

11. Coffman, E.G. Jr. and Hofri, M. A class of FIFO queues arising in computer systems. Operations Research, 26 , 5, (September-0ctober 1978), 864-880.

12. Couger, J.D. and Knapp, R.W. (ed.). Systems Analysis Techniques, John Wiley \& Sons, (1974).

13. Cumming, P.D., Kendall, K.E., Pegels, C.C., Seagle, J.P. and Shubsda, J.F. A collections planning model for regional blood suppliers: description and validation. Management Science, 22, 9, (May 1976), 962-971.

14. Daniel, D.R. Management information crisis. Harvard Business Review, (September-October $1 \overline{9} 617$, TII ff.

15. De, P., Haseman, W.D. and Kriebel, C.H. Toward an optimal design of a network database from relational descriptions. Operations Research, 26, 5, (September-October 1978), 805-823.

16. Dickson, G.W., senn, J.A. and Chervany, N.L. Research in management information systems: The Minnesota experiments. Management science, 23, 9 , (May 1977), 913-923. 
17. Frankfurter, G.M., Kendal1, K.E. and Pegels, C.C. Management control of blood through a short-term supply-demand forecast system. Management Science, 21 , 4, (December 1974) $\div 444-452$.

18. Garrity, J. Top management and computer profits. Harvard Business Review, (July-August 1, $\overline{963}$ ).

19. Gerrity, T.P., Jr. Design of man-machine decision systems: an application to portfolio management. Sloan Management Review, 12, 2, (Winter 1971), 59-75.

20. Hamilton, W.F. and Moses, M.A. A computer-based corporate planning system. Management Science, 21, 2, (October 1974), 148-159.

21. Hanssmann, F. (ed.). Operational Research in the Design of Electronic Data Processing systems, Crane, Russak \& Co., New York, (1973).

22. Higgins, J.C. and Roman, D.J. Socio-political forecasting and management information systems. Omega, $8,3,(1980)$. 303-309.

23. Hoffman, G.M. The contribution of management science to management information. Interfaces, 9, 1, (November 1978), 34-39.

24. Hyde, A.C, and Shafritz, J.M. HRIS : introduction to tomorrow's system for manaing human resources. Public Personnel Management, 6, 2, (March-April 1977), 70-77.

25. Inglehart, D.L. and Shedler, G.S. simulation of response times in finite-capacity open networks of queues. Operations R e s e a $\frac{\mathrm{r}}{\mathrm{c} h}, 2 \frac{2}{6}, 5$,

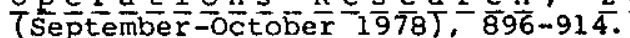

26. Ives, B., Hamilton, S, and Davis, G.B. A framework for research in computer-based information systems. MISRC-WP-80-07, University of Minnesota, (February 1980) -- forthcoming in Management Science.

27. Kendall, K.E. A decentralized information and control system for blood management. Forthcoming in Journal of Systems and software, (1980).

28. Kendall, K.E. and Lee, S.M. Formulating blood rotation policies with multiple objectives. Forthcoming Management Science, (November 1980).

29. King, R.H. and Love, R.R., Jr. A management science approach to Kelly-Springfield's operating division. Forthcoming in Interfaces. (December $1980)$.
30. Kriebel, C.H. Information processing and programmed decision systems. Management science, (November 1969). $149-164$

31. Kriebel, C.H., Van Horn, R.L.. and Heames, J.T. (ed.). Management Information systems: progress and Perspectives, Carnegie Press, (1971).

32. Leavitt, H.J. and Whisler, T.L. Management in the 1980 's. Harvard Business Review, (Nov.-Dec. 1958), $41-48$.

33. Levin, K. D. and Morgan, H.L. A dynamic optimization model for distributed data bases. Operations Research, 26, 5, (September-october 1978), 824-835.

34. Lewy, P.M. The colliery model: a computer aid to planning at a colliery. Journal of the Operational Resea Society. 30, (1979), $1085-1095$.

35. Little, J.D.C. Models and managers: The concept of a decision calculus. Management Science, 16, 8, (April 1970), B466-485.

36. Lucas, H.C., Jr. An empirical study of a framework for information systems. Decision Sciences, 5, 1, (January 1974), 102-113.

37. Lucas, H.C., Jr. Performance and the use of an information system. Management Science, 21, (April 1975), 908-919.

38. Marshall, K.T. and Richards, F.R. The OR/MS Index 1952-1976, T.I.M.S. and O.R.S.A., (1979).

39. Mason, R.O. World models: Who is the

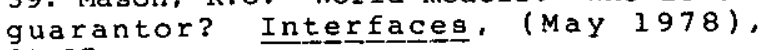
91-97.

40. McLean, E.R. and Riesing, T.F. MAPP: a DSs for financial planning, Data Base, 8, 3, (1977), 9-14.

41. Meador, C.L. and Ness, D.N. Decision support systems: An application to corporate planning. Sloan Management Review, 15, 2, (Winter $\overline{1974}$ ), $51-68$.

42. Meyer, N.D. The role of management science in office automation. Interfaces. 10, 1, (February 1980), 72-76.

43. Montgomery, D.B. and Urban, G.L. Marketing decision-information systems : an emerging view. Journal of Marketing Research, 7, (May 1970), 226-234.

44. Morgan, H.L. (ed.). Proceedings of the Wharton Conference on Research on Computers in organizations: Data Base, (winter 1973), and Special Report No. 2 , December 1973, The Society for Management Information systems. 
45. Morton, M.S.S. Management Decision Systems: Computer Based Support for Decision Making, Cambridge, Mass.: Division of Research, Harvard University. (1971).

46. Moses, M.A. Implementation of analytical planning systems. Management Science, 21, 10, (June 1975), 1) $133-1143$.

47. Nance, R.E. and Bhat, U.N. A processor utilization model for a muliprocessor computer system. Operations Research, 26, 5 .

48. Pounds, W.F. The process of problem finding. Industrial Management Review, (Fal1 1969), 1-19.

49. Radnor, M., Rubinstein, A.H. and Tansik, D. A. Implementation in $O R$ and $R \& D$ in government and business organizations. Operations Research, (Nov.-Dec. 1970), 967-991.

50. Raiborn, M.H. and Harris, W.T., Jr. Systems approach to model design. Cost and Management, (May-June 1974), 33-42.

51. Rockart, J.F. Chief executives define their own data needs. Harvard Business Review, (March-April 1979), 81-93.

52. Rosenkranz, R. An Introduction to Corporate Modeling, Duke University Press, Durham, N.C., (1979).

53. Schrieber, A.N. (ed.). Corporate Simulation Models, Graduate School of Business Administration, University of Washington, Seattle, Wash., (1970).
54. Siegel, s. and Torelli, P. The value of queueing theory: a case study. Interfaces, 9, 5, (November 1979), $148-151$.

55. Simon, H.A. The sciences of the Artificial, MIT Press, (1959).

56. Simon, H.A. The New Science of Management Decision, Revised Edition, Frentice-Hal1, (1977).

57. Sockut, G.H. A performance model for computer data-base reorganization performed concurrently with usage.

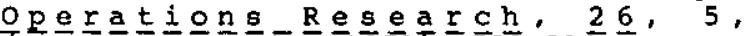

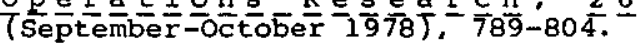

58. Stephenson, G.G. A hierarchy of models for planning in a division of I.C.I. Operational Research Quarterly, 21, 3, (1970), 221-245.

59. Tobin, N.R. Timesharing, interactive models and operational research. Operational Research Quarterly, 27, 3, i., $(1976), 531-545$.

60. Van Horn, R.L. Empirical studies of management information systems. Database, $5,2,3,4$, (Winter 1972), 172-180.

61. Wyman, P.F. Simulation of tar sands mining operations. Interface, 8,1 , Part 2. (November 1978), 6-20.

62. Zand, D.E. and Sorensen, R.E. Theory of change and the effective use of management science. Administrative Science Quarterly, 20, TDecember 1975), $532-545$. 


\title{
A CRITIQUE OF COGNITIVE STYLES THEORY AND RESEARCH
}

RONALD N. TAYLOR

Faculty of Commerce and Business Administration University of British Columbia

\section{IZAK BENBASAT}

Faculty of Commerce and Business Administration University of British Columbia

\begin{abstract}
Within the past decade many writers and researchers have recognized the importance of including psychological characteristics in managerial decision models. Cognitive styles have been singled out for research attention to determine their importance in information use and the acceptance of the recommendations made by management scientists. Despite the evidence that cognitive styles influence information processing in these contexts, conceptual and methodological weaknesses have seriously hampered the conclusiveness of cognitive syles research. Among the weaknesses evident in cognitive styles research studies are: 1) inadequately formulated theory of cognitive styles, 2) the use of a great many inadequately validated measuring instruments for assessing cognitive styles, and 3) faulty research designs. A review of the cognitive styles literature is presented; then these three problems are discussed and suggestions are made for correcting these limitations in cognitive styles research.
\end{abstract}

\section{INTRODUCTION}

Within the past decade, the accounting and mangement information (MIS) design literature has reflected an increased attention to the psychological characteristics of the decision maker. Research in this area has been stimulated by hypotheses such as "the utility of a particular type of information can not be effectively evaluated apart from the users of that information," (15, p. 518), and that "the designers of information systems should not force all psychological types to conform to one type of information system, rather each psychological type should be given the kind of in formation to which he is psychologically attuned and will use most effectively" $(30$, p. 478). A number of studies have empirically tested the impact of psychological charactistics on information system acceptance and use. Among the characteristics examined are tolerance for ambiquity (15), dogmatism $(25,37)$, risktaking propensity (37), and cognitive styles (9).
A recent report of the American Accounting Association Committee on Human Information Processing (2) states that an understanding of the variables and processes involved in human information processing and decision making is a prerequisite to improving human decisions. one of the psychological categories discussed in the above report and one which has received attention in the accounting and MIS literature is "cognitive styles." Witkin (44) defines cognitive styles as "the characteristic, self-consistent modes of functioning which individuals show in their perceptual and intellectual activities." Bariff and Lusk (4) have discussed three types of cognitive style which have relevance for managerial information systems design: 1) cognitive complexity, 2) field independence-dependence, and 3) systematic-heuristic.

These cognitive styles and the research which has investigated their roles in accounting and MIS are examined in this paper. The research evidence 